\title{
Benthos structure on tropical tidal flats of Australia
}

\author{
S. Dittmann \\ Zentrum für marine Tropenökologie, Klagenfurter Straße, GEO \\ D-28359 Bremen, Germany
}

\begin{abstract}
General features of benthos communities of tropical tidal flats are defined from northeast Australia, based on surveys from 1988 to 1991 in Hinchinbrook Channel and in the Haughton River estuary. A zonation of benthic communities is described. Total abundances for macrofauna averaged 31 individuals $200 \mathrm{~cm}^{-2}$, mesofauna (defined as infauna smaller than $0.5 \mathrm{~mm}$ and retained on a $0.25 \mathrm{~mm}$ sieve) averaged 16 individuals $10 \mathrm{~cm}^{-2}$ and meiofauna averaged 231 individuals $5 \mathrm{~cm}^{-2}$. The two study sites were similar in their abundance structures, but species numbers were higher in Hinchinbrook Channel (227) than in the Haughton estuary (96). This was due to a higher diversity of polychaeta in the Channel $\left(120\right.$ species, $\mathrm{H}^{\prime}=3.80$ vs. 29 species and $\mathrm{H}^{\prime}=$ 1.78 in the Haughton estuary). Species densities were comparable at both sites and rather low (6 species $177 \mathrm{~cm}^{-2}, 2-7$ species $10 \mathrm{~cm}^{-2}$ and 5 meiobenthic Plathelminth species $5 \mathrm{~cm}^{-2}$ ). Over $50 \%$ of the species encountered were represented by less than three individuals. Deposit feeders dominated the assemblages both in terms of individuals as well as species numbers. Tropical tidal flats are compared with their temperate counterparts and approaches for future research in tropical benthos communities are recommended.
\end{abstract}

\section{INTRODUCTION}

Why should intertidal benthos communities in the tropics differ in their structural and functional composition from their temperate counterparts? Geographical differences and a wider range of habitats were some of the factors proposed to produce a higher diversity in the tropics (Sanders, 1968). Yet the range of physical harshness is just as great within the same latitude as well as between latitudes and demand corresponding adaptations in either case. Theories on tropical-temperate differences developed on rather speculative backgrounds over the last decades are enjoying a revival of discussion as the variability in habitats and benthic communities in the tropics begins to be acknowledged. The recent increase in research in tropical soft-sediments has not confirmed the myth of higher diversity (Alongi, 1990). At present an unsuspected degree of similarity is encountered and analogue communities have been described in tropical and temperate seas (Reise, 1991; Vargas, 1987; Warwick \& Ruswahyuni, 1987). This is confronted by an awareness of our limited knowledge on tropical benthos in terms of taxonomy and descriptive biology as well as ecological processes determining the communities and whether the analogies we see imply similar functioning on the ecosystem level. Tidal flats in tropical northeast Australia were investigated, including surveys to provide information on the benthic animals and their zonation patterns. The same methods and approaches as were established for intertidal research in the Königshafen at the island of Sylt (Reise, 1985) were applied. Detailed accounts on species associations and interactions are in preparation. As a synthesis, the aim of this paper is to present major aspects 
of benthos communities in the investigated tropical tidal flats, to point out criteria that differ from their temperate counterparts, and to develop perspectives for future research.

\section{STUDY AREA AND METHODS}

Two tidal flats were studied along the northeast coast of Queensland (Fig. 1). On the landward side of Hinchinbrook Channel $\left(18^{\circ} 20^{\prime} \mathrm{S}, 146^{\circ} 3^{\prime} \mathrm{E}\right)$ tidal flats extend as a $0.5 \mathrm{~km}$

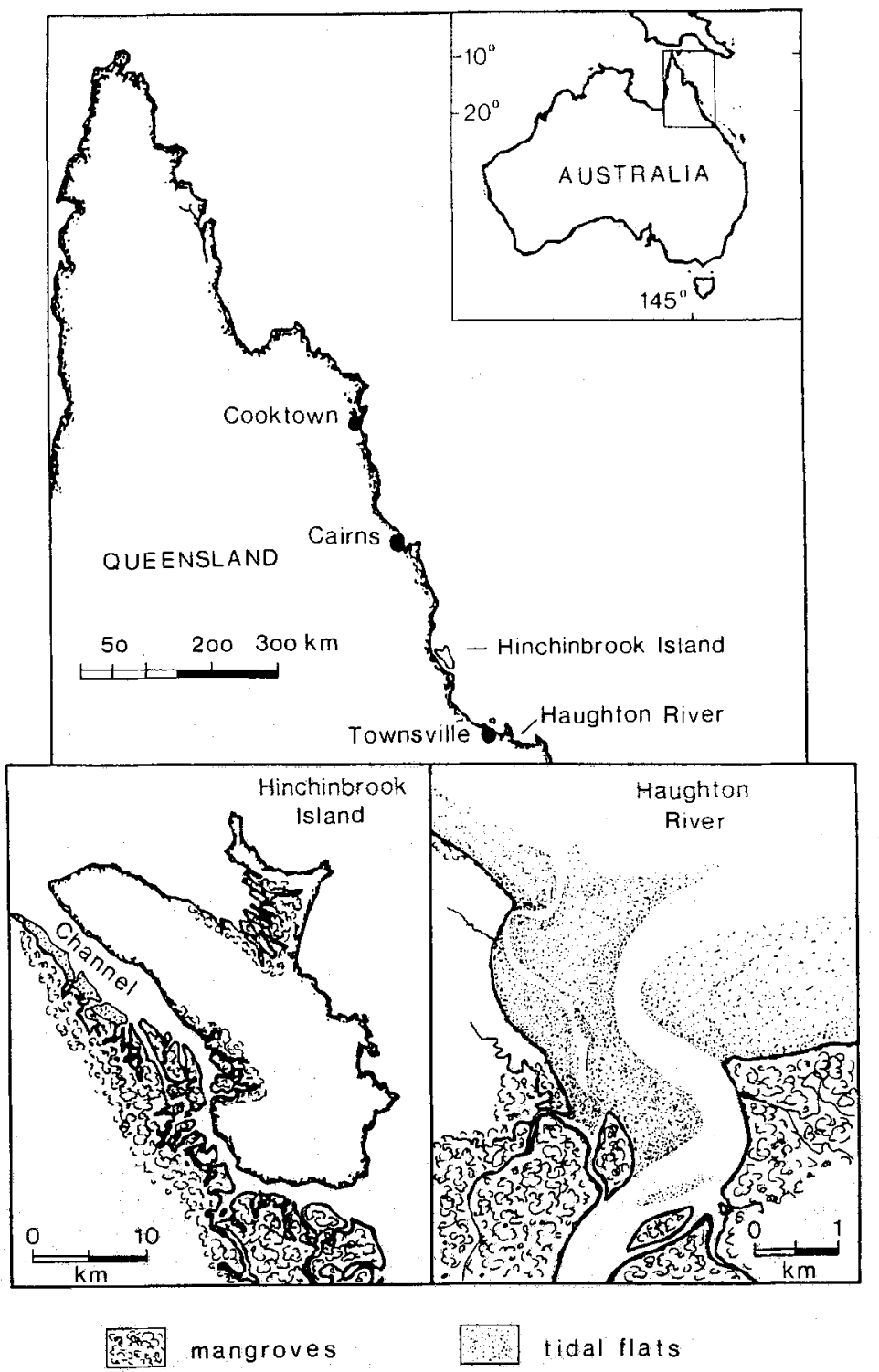

Fig. 1. Location of the tidal flats studied on the northeast coast of Australia 
wide fringe between the mangroves and the subtidal. An extensive tidal flat area $\left(5 \mathrm{~km}^{2}\right)$ lies in the mouth of the Haughton River, flowing into Bowling Green Bay $\left(19^{\circ} 25^{\prime} \mathrm{S}, 147^{\circ}\right.$ $5^{\prime}$ E). Hinchinbrook Island is located at the southern end of the wet tropics; whereas the Haughton River lies in the dry tropics and has more seasonal summer rainfall. Sediment was finer in the Haughton estuary than in the Channel and not well sorted at both sites (Table 1). Tides are semidiurnal and the current flows southward along the Queensland coast. Salinity was marine over most of the year and can vary between 25 and $41 \%$, according to Alongi (1988).

Table 1. Physical parameters at the two tropical tidal flats studied

\begin{tabular}{|lcc|}
\hline Physical parameter & Hinchinbrook Channel & Haughton estuary \\
\hline Temperature $\left({ }^{\circ} \mathrm{C}\right)$ & & \\
summer & 31 & 29 \\
winter & 26 & 26 \\
Total annual rainfall $(\mathrm{mm})$ & 2334 & 1152 \\
Average monthly rainfall & & \\
summer (mm) & 310 & 181 \\
winter $(\mathrm{mm})$ & 79 & 11 \\
Tidal range neap $(\mathrm{m})$ & 0.6 & 0.6 \\
Tidal range spring $(\mathrm{m})$ & 2.4 & 2.3 \\
Median grain size $(\mathrm{mm})$ & 0.42 & 0.12 \\
Sorting coefficient & 1.70 & 1.32 \\
Organic matter $(\% \mathrm{dw})$ & 2.45 & 2.37 \\
\hline
\end{tabular}

The benthos communities were assessed by qualitative mapping and quantitative sampling. Two locations in Hinchinbrook Channel were surveyed on five occasions over four years (November 1988, May 1989 and 1990, October 1989 and 1991). On each occasion and site, 6-10 samples were taken randomly for every benthos size (macro-, meso- and meiobenthos). In the Haughton estuary, five sites were sampled in April and September 1991 with 5 replicate samples each and for every benthos size. These sites lay along a transect from the high (mudflats) to the low intertidal (sandflats). Core sizes used were $177 \mathrm{~cm}^{2}$ for macrofauna, $10 \mathrm{~cm}^{2}$ for mesofauna (small macrofauna) and $5 \mathrm{~cm}^{2}(1.8$ $\mathrm{cm}^{2}$ in muddy sediments) for meiofauna. Macrobenthos samples were taken to a sediment depth of $20 \mathrm{~cm}$, all other samples to $5 \mathrm{~cm}$. Sieve sizes used were $1 \mathrm{~mm}$ for macrofauna (Hinchinbrook Channel) and $0.5 \mathrm{~mm}$ in the Haughton estuary (to account for the finer grain size here), for mesofauna $0.25 \mathrm{~mm}$ and for meiofauna $0.062 \mathrm{~mm}$. All samples were treated alive. Macrofauna was sieved through the coarser sieves and sorted visually from sorting trays. Samples for mesofauna and meiofauna were repeatedly decanted through the respective sieve sizes and counted under a dissecting microscope.

\section{RESULTS}

The following scheme of the zonation of benthos communities emerged, defined by macrobenthic organisms structuring the specific sediment (Fig. 2). Mudflats in the higher intertidal were characterized by assemblages of macrophthalmid crabs, fiddler crabs and 


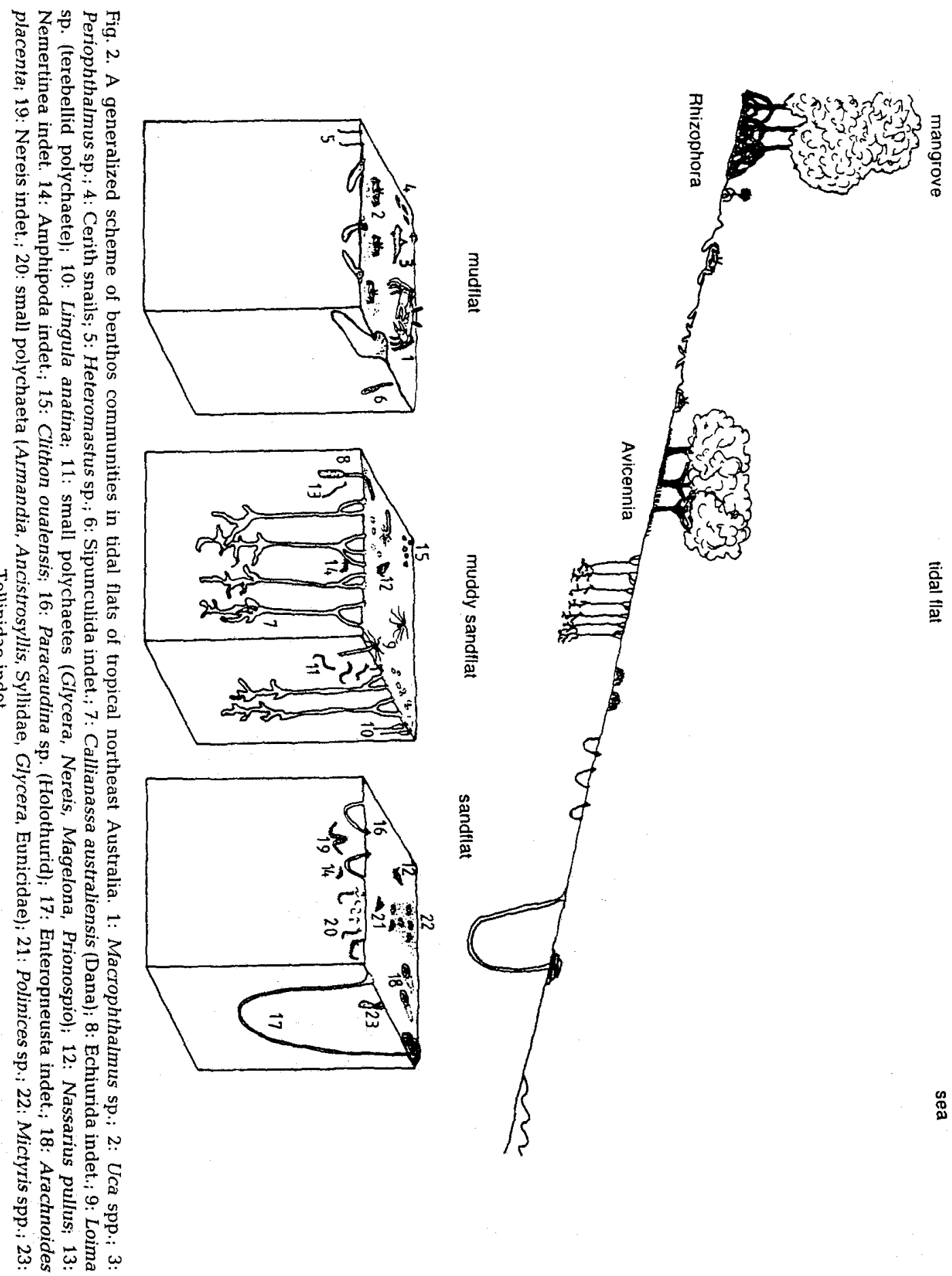


mudskippers. Patches of cerith snails were frequently encountered in this region. The muddy-sand mid-intertidal areas were inhabited by callianassid shrimps. In Hinchinbrook Channel assemblages of brachiopods occurred in this region. Sandflats in the lower intertidal were home for a benthic holothurid and enteropneusts. Sanddollars were frequently found at the edge to the subtidal. Migratory crabs (Mictyris spp.) were encountered throughout the tidal flats.

The species stock of benthic organisms was not yet sufficiently sampled with $250 \mathrm{~m}^{2}$ of sediment turned over (Fig. 3). A low species frequency was typical of both study sites. Over $50 \%$ of the species occurred with one to three individuals only (Fig. 4). Species densities were low as well, but, differentiated by benthos size, higher species densities were encountered with smaller corers and sieve sizes used (Table 2). Polychaeta and Crustacea were richest in species and polychaetes accounted for $53 \%$ (Hinchinbrook Channel, $\mathrm{H}^{\prime}=3.80$ ) and $30 \%$ (Haughton estuary, $\mathrm{H}^{\prime}=1.78$ ) of the species (Table 2). The percentage share of crustacea of the total species number was higher in the Haughton $(33 \%)$ than in the Channel $(17 \%)$.

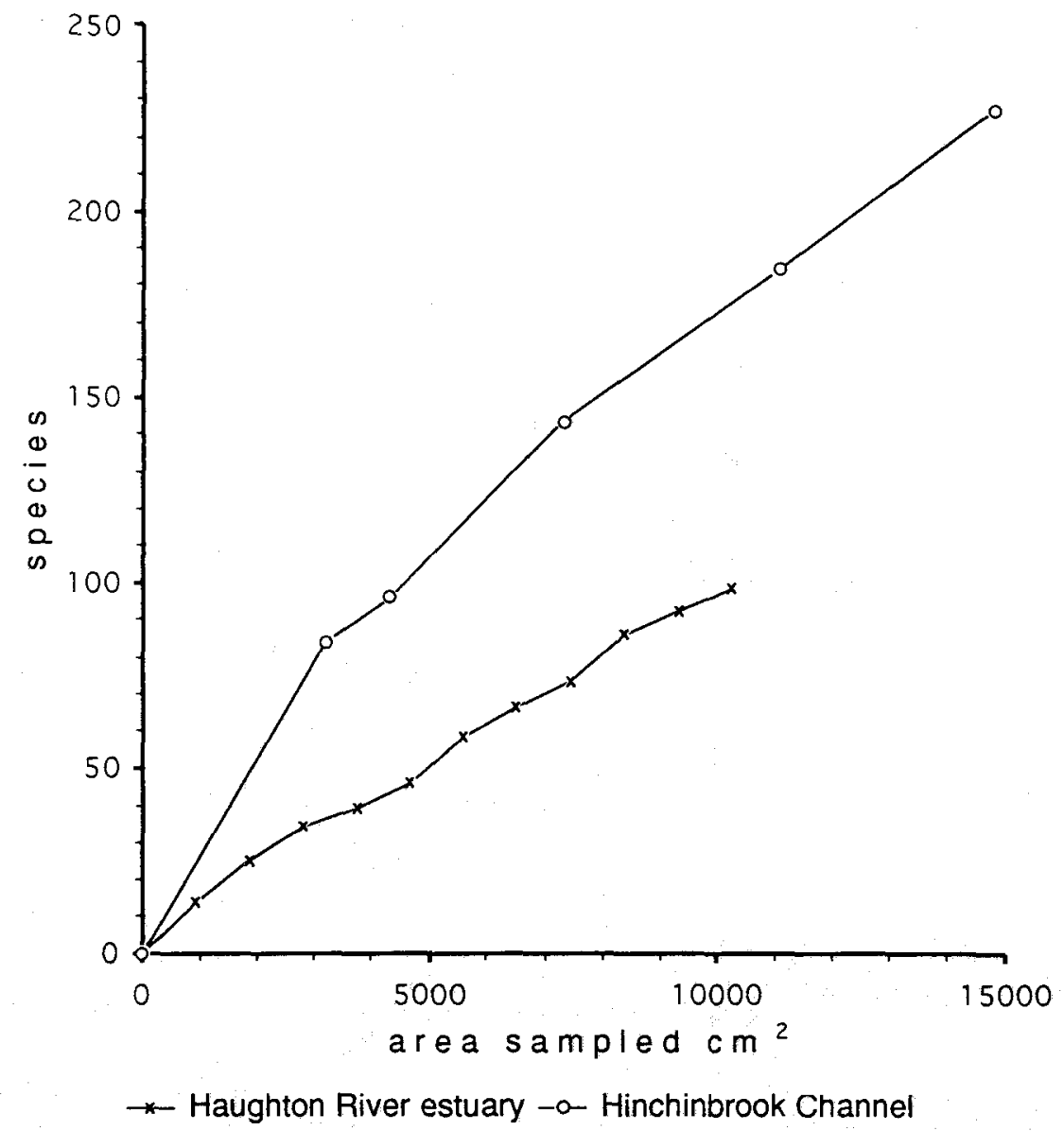

Fig. 3. Species-area curves of macrobenthic taxa collected in samples for macro- and mesofauna 


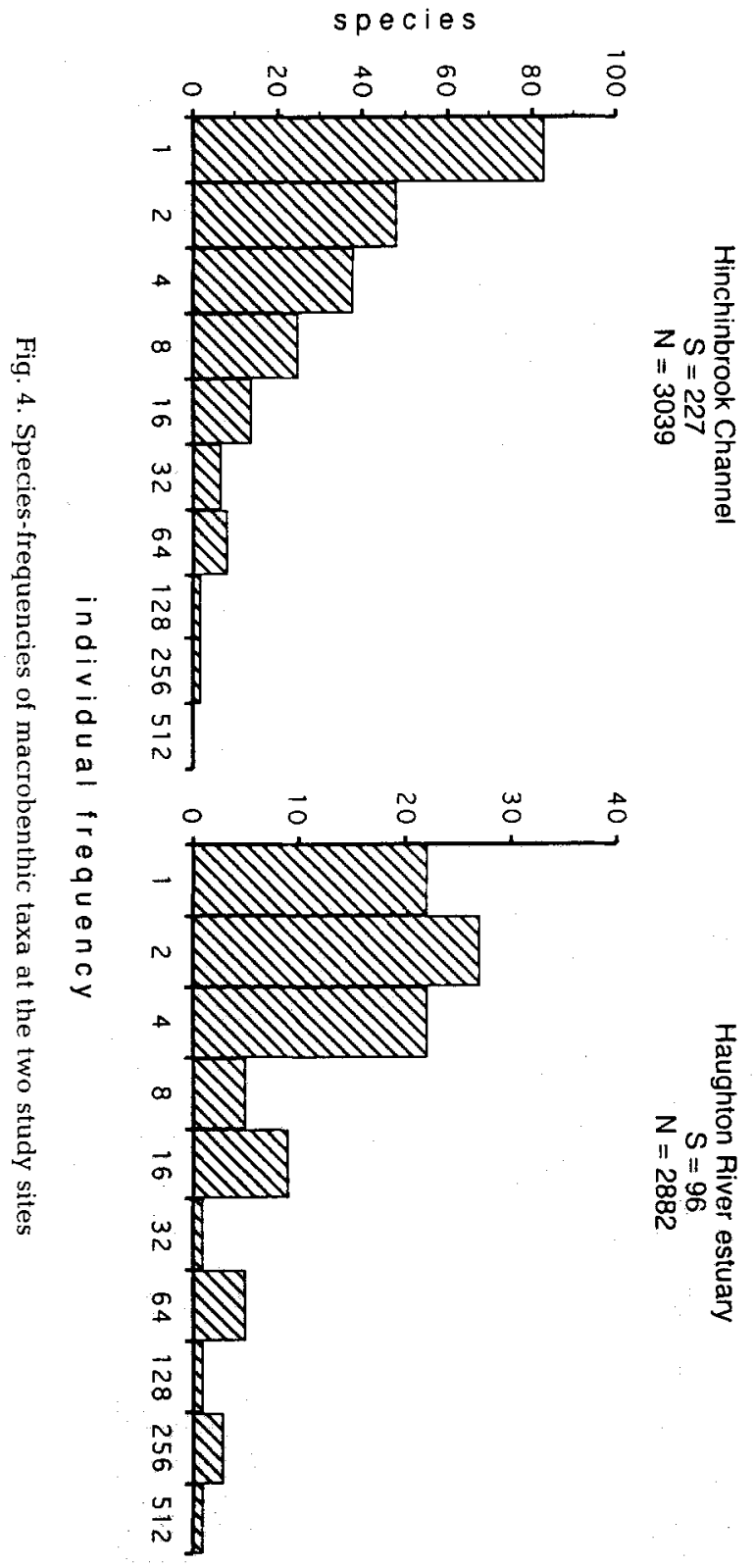


Table 2. Species numbers and densities of benthic organisms in two tidal flats of the Queensland coast. The data are based on a total of 238 samples taken over three years in Hinchinbrook Channel and a total of 172 samples taken in the Haughton estuary within one year. "Others" include macrobenthic taxa with few recordings, such as Nemertines, Brachiopods, Oligochaeta, Sipunculida, Enteropneusta, Acrania and Anenomes. Plathelminthes were the only meiobenthic taxon treated on species level and their species numbers are not included in the total given for the "classic" macrobenthic fauna, which comprises records from meso- and meiofaunal samples

\begin{tabular}{|lcc|}
\hline Organisms & Hinchinbrook Channel & Haughton estuary \\
\hline Species n u m bers & & \\
Total & 227 & 96 \\
Polychaeta & 120 & 32 \\
Crustacea & 38 & 13 \\
Bivalves & 25 & 10 \\
Gastropoda & 24 & 4 \\
Echinodermata & 6 & 8 \\
"Others" & 14 & 44 \\
Platyhelminthes & 71 & \\
Species den siti es & & $5.2 \pm 2.6$ \\
Total macrofauna $\left(177 \mathrm{~cm}^{2}\right)$ & $6.3 \pm 3.4$ & $2.3 \pm 1.3$ \\
Total mesofauna $\left(10 \mathrm{~cm}^{2}\right)$ & $7.5 \pm 3.6$ & $2.0 \pm 1.5$ \\
Polychaeta macro & $1.7 \pm 1.5$ & $1.2 \pm 0.9$ \\
meso & $3.6 \pm 2.3$ & $1.5 \pm 1.1$ \\
meio & $2.7 \pm 1.7$ & $1.5 \pm 1.1$ \\
Crustacea macro & $0.7 \pm 0.8$ & $0.4 \pm 0.5$ \\
meso & $1.2 \pm 1.0$ & $0.8 \pm 0.7$ \\
Bivalves macro & $1.4 \pm 1.7$ & - \\
Gastropoda macro & $1.1 \pm 1.1$ & $0.3 \pm 0.6$ \\
meso & $1.5 \pm 1.3$ & $0.2 \pm 0.4$ \\
Platyhelminthes $\left(5 \mathrm{~cm}^{2}\right)$ & $0.7 \pm 0.9$ & $4.3 \pm 3.3$ \\
\hline
\end{tabular}

Total benthic abundances of all size categories were similar at both study sites (Table 3). Polychaetes accounted for 27 to $36 \%$ of individual numbers. Mesofaunal-sized Polychaeta were more abundant in Hinchinbrook Channel than macrofaunal-sized ones, both in terms of species numbers and densities (Tables 2 and 3). Crustacea caught in mesofaunal samples were mainly amphipods; whereas decapod crustaceans were collected in macrofaunal samples. These crabs were more abundant in the Haughton estuary. Here, crustacea accounted for $21 \%$ of the individuals compared to $12 \%$ in the Channel. The high score for bivalves in the Haughton estuary was due to a single sample taken in the sandflat in September 1991 containing 510 juvenile tellinid mussels. Within the meiofauna, nematodes were the most numerous taxon (about $70 \%$ ), followed by copepods $(17 \%)$ and platyhelminthes $(5 \%)$. For a comparative view on individual densities of the benthic size-classes, the abundances were transformed to $100 \mathrm{~cm}^{-2}$ (Fig. 5). Due to the high variability in abundances (note the high standard deviations in Table 3) and unknown aggregation patterns of tropical infauna, this was preferred to an extrapolation to $1 \mathrm{~m}^{-2}$. Smaller size-classes $(<0.5 \mathrm{~mm})$ were more numerous, encompassing both juvenile stages of macrofauna as well as macrofauna maturing within this 


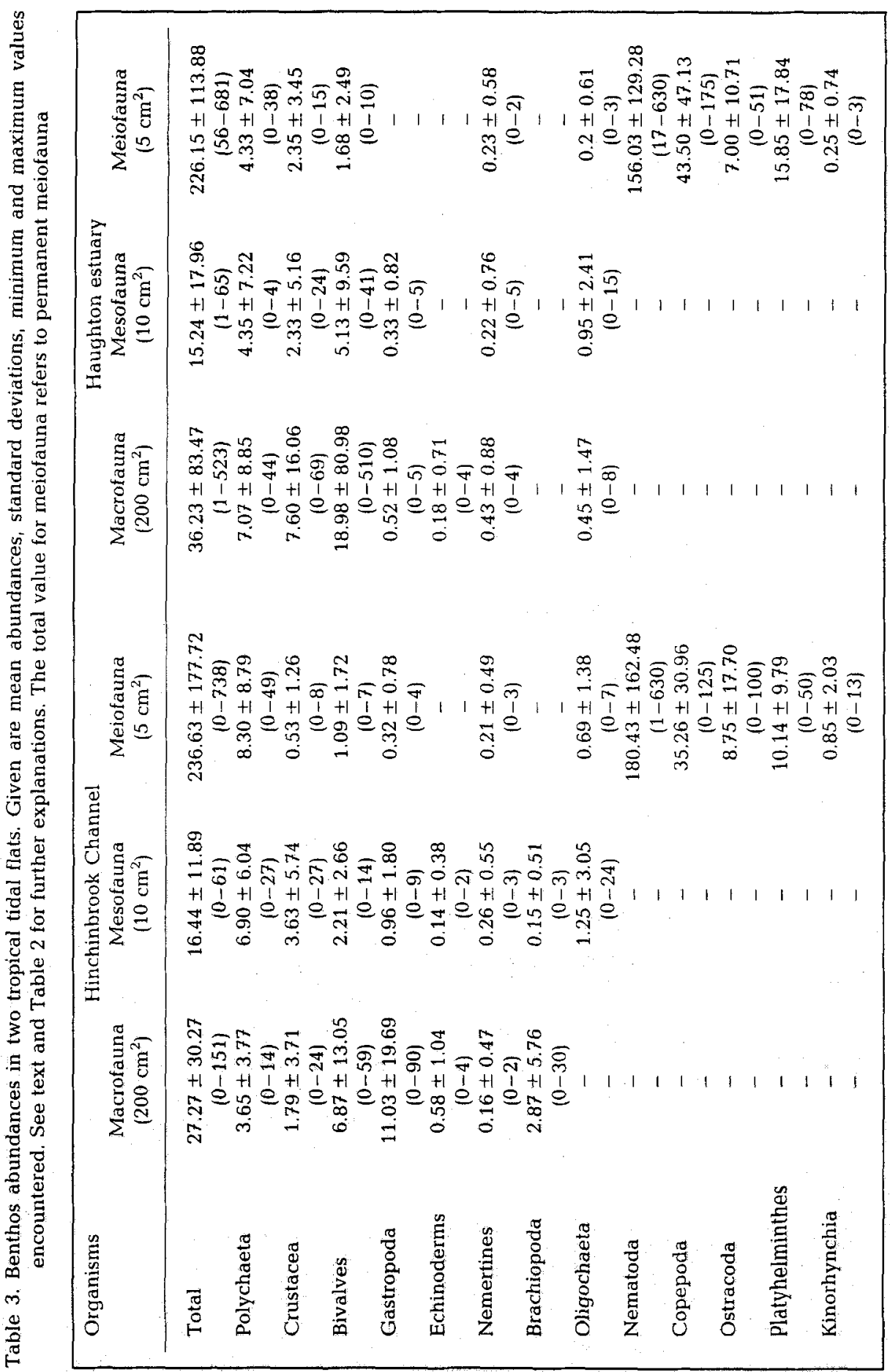




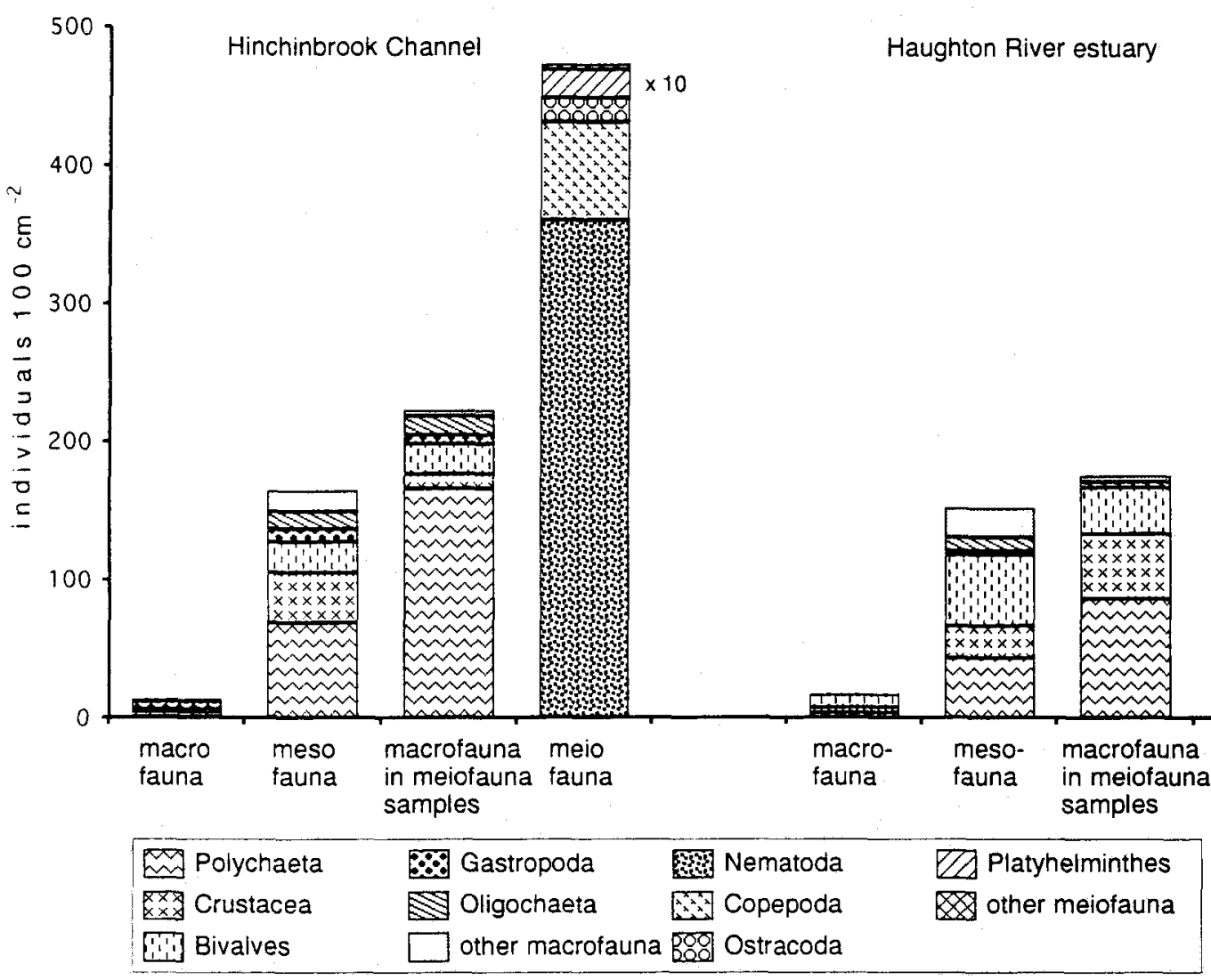

Fig. 5. Average benthic abundances for all infaunal categories calculated to $100 \mathrm{~cm}^{2}$ of sediment. Macrofauna in meiofauna samples includes mesofauna and temporary meiofauna (juvenile stages). Meiofaunal numbers have to be multiplied by 10

mesofaunal-size range (polychaetes and crustaceans) and bivalves which did not develop beyond the juvenile stage.

Looking at the benthic fauna of tropical tidal flats from the perspective of functional modes, mobility and deposit-feeding emerged as distinctive. Mobile species (esp. ocypodid, mictyrid and macrophthalmid crabs whose population densities were assessed qualitatively) were more prominent in species and individual numbers than sessile species. As a feeding strategy, deposit-feeding appeared advantageous, as depositfeeders dominated the communities in terms of species and individuals (Fig. 6). This pattern was similar in both tidal flats. Filter-feeders constituted less than $20 \%$ of the faunal composition, the higher share in the Haughton estuary was due to the sample mentioned above. In neither study area did bivalves attain sizes bigger than $1 \mathrm{~cm}$ and they did not aggregate to form beds. About a quarter of the species were predators, but these occurred with few individuals. 

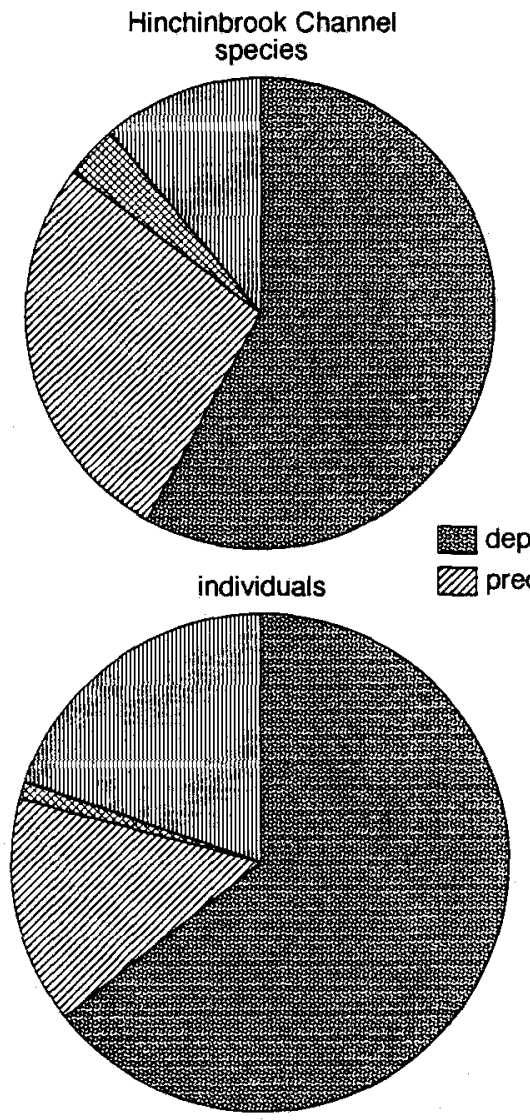

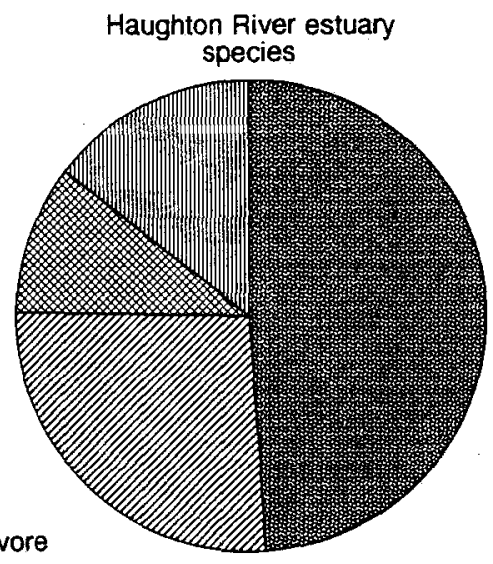

individuals

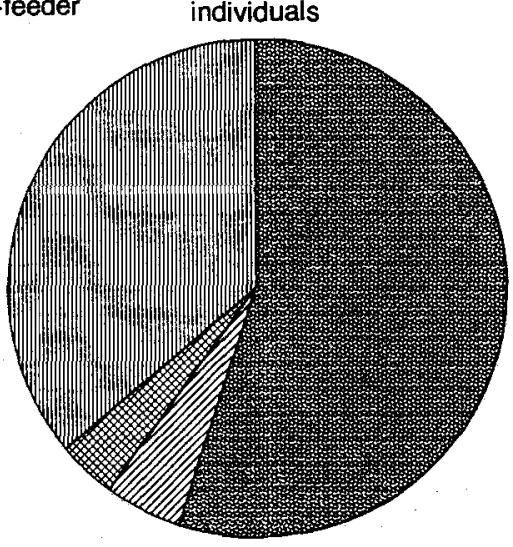

Fig. 6. Composition of feeding modes in the macrobenthic assemblages of the two tropical tidal flats studied. The full circle represents $100 \%$

\section{DISCUSSION}

Research in tropical areas is hampered by the little amount of information available on taxonomy, natural histories and population dynamics of the organisms involved. Thus, species accounts often remain tentative and the interpretation of findings is obscured by unknown autecological aspects. Species numbers will increase with further sampling and taxonomic endeavours. Compared to temperate tidal flats, macrobenthic species numbers are higher in the tropics (Reise, 1991). This trend, applied to crustacea and molluscs, can be confirmed from tidal flats in NE Australia, where polychaetes emerged as a further group rich in species. The use of smaller sieve sizes contributed to the high species numbers of polychaetes recorded here. Polychaeta also contributed the most species to the benthos community in a central American mudflat studied by Vargas (1987). Species numbers of meiofaunal platyhelminthes were lower than in temperate tidal flats, but the taxonomic composition and diversities in corresponding sediment types were comparable with worldwide findings (Dittmann, 1991). 
Abundances of benthos in NE Australia amounted to 158 ind $\mathrm{m}^{-2}$ for macrofauna and 15840 ind $\mathrm{m}^{-2}$ for mesofauna. These values are higher than those reported from other southeast Asian locations (see Reise, 1991) and more comparable to abundances on the coast of Costa Rica (Vargas, 1987, 1988a). Yet, they were considerably lower than abundances from temperate intertidal (Reise, 1985, 1991). The trend of lower individual and higher species numbers for the tropics can be confirmed. Diversity however, as expressed by Shannon-Weaver's index, remained within the range of $\mathrm{H}^{\prime}=1-4$ for the polychaetes in this study, for the benthos in a Costa Rican mudflat (Vargas, 1987, see also review by Alongi 1990 for other tropical sites) and for benthos in a temperate tidal flat (Dittmann, 1990). Meiofauna numbers were dominated by nematodes in this study $(70 \%)$, in Costa Rica (82\%, Vargas, 1988b) and in the temperate bay of Königshafen (37-61\%, Reise, 1985). Alongi (1987) reported platyhelminthes (turbellaria) as the dominating meiofaunal group in tropical sediments, which could not be confirmed here (Dittmann, 1991). Small-sized macrofauna was abundant in all intertidal areas studied along the tropical Queensiand coast (Fig. 5). The mesh size of $0.25 \mathrm{~mm}$ used in this study obtained high density values for this size-class of benthos previously missed by studies using 1 or $0.5 \mathrm{~mm}$ sieves for macrofauna, and sieves with a $0.25 \mathrm{~mm}$ mesh are recommended for further benthic studies. A similar approach of stratified sampling was applied by Reise (1991), who separated sediment layers of core samples, sieving upper horizons through finer mesh $(0.25$ and $0.5 \mathrm{~m})$ than lower sediment layers $(1 \mathrm{~mm})$. Separate sediment cores were taken in this study to evaluate densities of benthic-size categories. The small macrofauna trapped on a $0.25 \mathrm{~mm}$ sieve were termed as mesofauna, as this mesh lies between the classical sieve size distinctions for macro- and meiofauna (McIntyre, 1969). They do not live interstitially and do not share life strategies with the permanent meiofauna. They differ from temporary meiofauna (juvenile stages of macrofauna) in that they mature in this size-class. The concept of a mesofauna intermediary between meio- and macrofauna also implies a different web of processes in the benthic realm of (tropical) sediments, which calls for further investigations. At the other end of the size-scale, "megabenthic" organisms were difficult to quantify as their population densities are not assessable with corers. Crabs in the mudflat for example, retreat into their burrows as soon as people are present and it remains unknown which percentage of the population will emerge again. Attempts to evaluate densities of crabs by a balloonsuspended camera failed. Burrows can reach a considerable depth (e.g. $>1 \mathrm{~m}$ for C. australiensis (Kenway, 1981)) exceeding every effort to dig residents out of their hole. Holothurids in the sandflat were often inactive and no faecal casts could be seen during many visits to the field. So far, "megabenthic" population areas were estimated by qualitative mapping and found to relate to the main sequence of sediment types from the high to the low intertidal regions. They are the organisms structuring the benthic realm, thus providing living space for associated fauna, generating a respective biocoenosis (Fig. 2). Thus, the benthos communities will be defined according to the classical concept of biocoenosis (Reise, 1980). The naming of the communities will follow in a further publication, together with a description of the associated infauna.

To overcome the problem of taxonomic hazards, functional modes were classified, an approach leading to turther questions of why mobility is advantageous, why there are no filter-feeders and how is the food web resulting in a dominance of deposit-feeders. These questions have to be addressed in future research. A look at functional modes is useful, 
but, especially for tropical tidal flats, classifications are often speculative due to a lack of information on natural history.

The low species density and the high variability in abundances, even of frequent species, add a high degree of uncertainty to spatial distributions of infauna in tropical sediments. This has to be addressed by extensive and elaborate sampling schemes. Small-scale distribution patterns are also affected by biotic interactions. Field experiments revealed predation by foraging crabs on meiofauna (Dittmann, 1993) and accommodation of infauna in burrows of callianassid shrimps (Dittmann, unpubl.). These experiments showed that the role of predation and accomodation in structuring intertidal fauna, as proven for temperate tidal flats (Reise, 1985), are very applicable to their tropical counterparts. Cages excluding macropredators changed the species composition in a tropical mudflat studied by Vargas (1988a), yet he considered macrobenthic predation unimportant. More field experiments should be carried out in tropical tidal flats to gain insight into the ecological processes structuring their communities and to compare functional attributes of community composition between tropical and temperate counterparts.

In conclusion, the need for small teams of scientists should be emphasized, comprising taxonomy, population dynamics, community ecology, microbiology and sediment chemistry as their background. Their collaboration on concise (experimental) projects would incorporate the historical sequence of descriptive, analytical and modelling approaches. These joint ventures could tackle questions mentioned above of biodiversity, ecological processes, trophodynamics and detrital flow, aiming to generate management and conservation strategies for tropical coastlines which are under increasing environmental pressure.

Acknowledgements. The hospitality and facilities at the Australian Institute of Marine Science were very much appreciated. A lot of the field work would not have been possible without all the manand woman power volunteered by C. Bone, U. Böttcher, M. Cappo, J. van Kampen, C. Lovelock, F. Micheli, K. Perrot, U. Siebeck, J. Sharp, D. Smallwood, A. Taplin, the crew of the RV "Harry Messel" and many others. The project was funded by a postdoctoral scholarship of the Deutsche Forschungsgemeinschaft (IIO2-Di396/1-2).

\section{LITERATURE CITED}

Alongi, D. M., 1987. Intertidal zonation and seasonality of meiobenthos in tropical mangrove estuaries. - Mar. Biol. 95, 447-458.

Alongi, D. M., 1988. Microbial-meiofaunal interrelationships in some tropical intertidal sediments. J. mar. Res $46,349-365$.

Alongi, D. M, 1990. The ecology of tropical soft-bottom benthic ecosystems. - Oceanogr. mar. Biol. $28,381-496$.

Dittmann, S., 1990. Mussel beds - amensalism or amelioration for intertidal fauna? - Helgoländer Meeresunters. 44, 335-352.

Dittmann, S., 1991. Plathelminthes in tropical intertidal sediments of northeastern Australia. Hydrobiologia 227, 369-374.

Dittmann, S., 1993. Impact of foraging soldiercrabs (Decapoda, Mictyridae) on meiofauna in a tropical tidal flat - Revta Biol. trop. 41, 299-309.

Kenway, M., 1981. Biological studies of Callianassa australiensis (Dana). Thesis, Univ. Townsville.

McIntyre, A. D., 1969. Ecology of marine meiobenthos. - Biol. Rev. 44, 245-290.

Reise, K., 1980. Hundert Jahre Biozönose. - Naturw. Rdsch., Stuttg. 8, 328-335.

Reise, K, 1985. Tidal flat ecology. Springer, Berlin, $191 \mathrm{pp}$. 
Reise, K., 1991. Macrofauna in mud and sand of tropical and temperate tidal flats. In: Estuaries and coasts: spatial and temporal intercomparisons. Ed. by M. Elliott \& J.-P. Ducrotoy. Olson \& Olson, Fredensborg, 211-216.

Sanders, H. L., 1968. Marine benthic diversity: a comparative study. - Am. Nat. 102, 243-282.

Vargas, J. A., 1987. The benthic community of an intertidal mudflat in the Gulf of Nicoya, Costa Rica. - Revta Biol. trop. 35, 299-316.

Vargas, J. A., 1988a. Community structure of macrobenthos and the results of macropredator exclusion on an intertidal mudflat. - Revta Biol. trop. 36, 287-308.

Vargas, J. A., 1988b. A survey of the meiofauna of an eastern tropical Pacific intertidal mudflat. Revta Biol. trop. 36, 541-544.

Warwick, R. M. \& Ruswahyuni, 1987. Comparative study of the structure of some tropical and temperate marine soft-bottom macrobenthic communities. - Mar. Biol. 95, 641-649. 